\title{
Comparative study to evaluate the prevalence of deranged lipid profile and oral glucose tolerance test in polycystic ovarian syndrome patients with normal females: a prospective observational study
}

\author{
Isha Rani Phutela ${ }^{1}$, Basharat Hussain Pandit ${ }^{1}$, Asia Ashraf ${ }^{2}$, Sadia Ali Wani ${ }^{3}$, Mehraj Ud Din ${ }^{4 *}$
}

\begin{abstract}
${ }^{1}$ Department of Obstetrics and Gynecology, ${ }^{3}$ Department of Anaesthesiology and Critical Care Medicine, Batra Hospital and Medical Research Centre, New Delhi, India

${ }^{2}$ Department of Obstetrics and Gynecology, ${ }^{4}$ Department of Anaesthesiology and Critical Care Medicine, Government Medical College Srinagar, Jammu and Kashmir
\end{abstract}

Received: 20 September 2017

Accepted: 27 October 2017

\section{*Correspondence: \\ Dr. Mehraj Ud Din, \\ E-mail: mearajdin@gmail.com}

Copyright: () the author(s), publisher and licensee Medip Academy. This is an open-access article distributed under the terms of the Creative Commons Attribution Non-Commercial License, which permits unrestricted non-commercial use, distribution, and reproduction in any medium, provided the original work is properly cited.

\section{ABSTRACT}

Background: PCOS is a complex endocrine disorder characterized by menstrual dysfunction, anovulation, infertility and hyper androgenic symptoms with dyslipidaemia, cardiovascular diseases, and impaired glucose tolerance and type II diabetes mellitus. Multiple risk factors are involved in the pathogenesis of PCOS.

Methods: A comparative evaluation of deranged lipid profile and OGTT in PCOS patients with normal females was done in patients with age group of 15 to 30 years. The Rotterdam criteria for PCOS was used for selection of the participants prospectively and a detailed history regarding period of amenorrhea, menstrual cycles, obstetric history, any past history of medical disorder were taken followed by general physical, systemic and obstetric examination. All the patients underwent Ultrasound examination, OGTT and lipid profile, prolactin, 17-OH progesterone and testosterone level.

Results: A significant association of PCOS with deranged lipid profile and blood glucose tolerance and obesity was observed. Patients with PCOS had higher prevalence of oligomenorrhoea, infertility, hirsutism and acne. Furthermore, a statistically significant trend was seen where signs and symptoms like infertility, hirsutism and acne, deranged OGTT and dyslipidaemia were more frequently associated with increased BMI, sedentary life style intake of high calorie diets.

Conclusions: An association between obesity, sedentary lifestyle, and dietary factors with PCOS was observed which can be modified to improve the health condition of the women with PCOS.

Keywords: Dyslipidemia, Impaired glucose tolerance, Infertility, Metabolic syndrome, PCOS

\section{INTRODUCTION}

The polycystic ovary syndrome (PCOS) is a complex endocrine disorder of unknown cause, characterized by oligomenorrhoea or anovulation and hyper androgenic symptoms such as the presence of acne and hirsutism. The etiopathogenesis of this genetically complex disorder is multifactorial involving both genetic and environmental factors. The condition often exhibits the association of psychological impairments and metabolic derangements such as insulin resistance and deranged lipid profile and Obesity. PCOS is known to have longterm consequences among women causing cardiovascular diseases, hormonal imbalances, cancers and type II diabetes mellitus. ${ }^{1}$ The prevalence rates of PCOS varies from $7 \%$ to $10 \%$ in one study to about $15 \%$ to $20 \%$ 
according to the European Society for Human Reproduction and Embryology. ${ }^{2}$ Among these, about $50 \%$ to $70 \%$ present with insulin resistance which leads to other comorbidities such as hypertension, diabetes, dyslipidemia, obesity and metabolic disorder. ${ }^{3}$ The prevalence of the disease ranges from $2.2 \%$ to $26 \%$ among the age group of 18 to 45 years in India. ${ }^{4}$ About $4 \%$ to $10 \%$ of the women of reproductive age group manifest the symptoms during puberty. ${ }^{5}$ Based on the Rotterdam consensus, the prevalence of PCOS was $20 \%$ to $25 \%$ while with US-NIH criteria was $4 \%$ to $10 \% .^{6}$ The women with PCOS present with menstrual disturbances such as amenorrhea and oligomenorrhoea, symptoms of hyperandrogenaemia such as hirsutism and acne, dyslipidaemia, insulin resistance and infertility and the prevalence of hyperandrogenism in women with PCOS is $74.2 \%$ and $50.6 \%$ among obese and non-obese women in India. $^{7}$

Obesity is considered a risk factor and obesity in the presence of PCOS causes complications in the normal function of the body. It has been observed that menstrual irregularities were more common in obese $(79.2 \%)$ than in non-obese $(44 \%)$ women while oligomenorrhoea did not show much difference among obese $(66.67 \%)$ and non-obese $(60 \%)$ women. ${ }^{7}$ A strong linear correlation of visceral fat to insulin resistance has been observed. Further, insulin resistance has closest correlation with visceral fat mass $(\mathrm{r}=0.68, \mathrm{P}<0.001)$ followed by waist circumference $(\mathrm{r}=0.62, \mathrm{P}<0.001)$. The weakest correlation was between the waist and hip $(\mathrm{r}=0.36, \mathrm{P}=$ $0.01)$. This implies that visceral mass contributes insulin resistance in PCOS. ${ }^{8}$

Insulin resistance is one of the common features of PCOS. The presence of insulin resistance is about 5 to 10 times more in women with PCOS than in normal women. ${ }^{9,10}$ Dyslipidaemia is another risk factor, which is associated with PCOS along with high BMI and insulin resistance. However, no clear-cut correlation has been observed between BMI and lipid parameters among women without insulin resistance while among insulin resistant women with PCOS, the lipid profile had high triglycerides, high-level of total cholesterol and lower high-density lipoprotein. ${ }^{11}$ Anovulation and oligomenorrhoea is a common sign which is experienced by women with PCOS common feature. About $65 \%$ of the women with PCOS had oligomenorrhoea. ${ }^{7}$ It has also been seen that about two-thirds of the women with PCOS do not ovulate regularly leading to infertility. ${ }^{12}$ Women with PCOS mostly complain about hirsutism, male pattern hair growth in the androgen dependent areas of the body, which is caused by hyper androgenic activity.

Women with hyper androgenic symptoms had significantly high BMI which suggests that obese women with PCOS tend to have hyperandrogenism and BMI could be a strong indicator for the presence of disorders of excessive androgen secretion. ${ }^{13}$
A lot of focus and research is currently being done in the subject of PCOS, and metabolic syndrome. Understanding of the enteropathogenesis of this complex disorder is believed to help in identifying and ultimately in the modification of these risk factors in order to improve the health of women with PCOS. The main objectives of the current study were to estimate the degree of deranged lipid profile and OGTT among PCOS patients and to compare the results with normal females.

\section{METHODS}

A prospective observational study was carried out for 18 months from April 2015 to October 2016 in the Department of Obstetrics and Gynecology and Department of Endocrinology at Batra Hospital and Medical Research Centre, New Delhi. Written informed consent was obtained from all the participants. All the patients attending the Department of Obstetrics and Gynecology in between the age group of 15 to 30 years were screened for inclusion in the study. A total of 154 women were enrolled for the study. 79 out of 154 women were diagnosed with PCOS on the basis of the Rotterdam criteria and were labeled as PCOS group and 75 women with any other gynecological complaints were randomly selected and this group was labeled as the control group. The study was approved by the hospital ethical committee.

Rotterdam criteria state that 2 out of the following 3 features should be present for fulfilling the diagnosis of poly cystic ovarian syndrome.

\section{- Oligomenorrhoea/amenorrhea}

- Sign of androgen excess like hirsutism, acne

- Presence of polycystic ovaries on USG (more than 12 follicle having $2 \mathrm{~mm}$ to $9 \mathrm{~mm}$ in size, increased ovarian volume more than $10 \mathrm{cc}$ ).

Patients with uterine and adnexal pathology like leiomyoma and ovarian cyst, associated hormonal imbalances like Hypo/hyperthyroidism, hyper prolactinemia, congenital adrenal hyperplasia and medical disorder i.e. diabetes, cardiac disease, and hypertension were excluded from the study. Detailed medical, obstetrical and gynecological history was taken with written consent from the participants. General physical, systemic and obstetric examination was done followed by laboratory and diagnostic evaluations such as TSH, Ultrasound examination, OGTT, lipid profile and examination of the serum levels of prolactin, 17-OH progesterone and testosterone. Baseline investigations like complete blood count, renal function tests with serum electrolytes and liver function tests were also done in all patients.

\section{Statistical analysis}

Mean with SD was calculated for continuous and frequency proportions and was used for the presentation 
of both the continuous and categorical variables. Data were entered and coded in MS Excel (2010) and the statistical software SPSS (Version 22, SPSS Inc., Chicago, IL, USA) was used for the entire analysis. Pie chart, was used for graphical presentation of the data. Student's t or Mann-Whitney ' $U$ ' test was used for finding the quantitative variables with two independent groups while Chi-square/Fisher's test was used for finding the statistical significance between qualitative variables. The ' $p$ ' value of less than 0.05 ( $p<0.05)$ was considered as statistically significant.

\section{RESULTS}

A total of 154 patients were enrolled in the study. Among 154 participants, 79 women were diagnosed with PCOS and 75 women with other gynaecological problems were under the control group as shown in Figure 1.

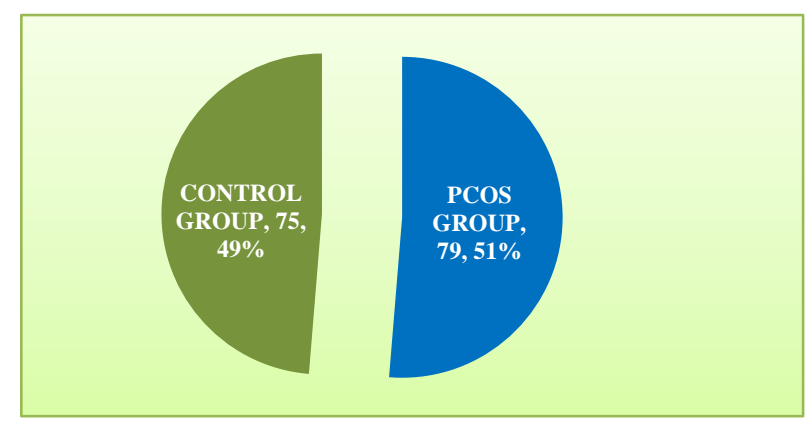

Figure 1: Distribution of cases in PCOS and control groups.
Table 1: Age, body mass index and menstrual cycle duration in two study groups.

\begin{tabular}{|c|c|c|c|}
\hline Parameter & PCOS & Control & p value \\
\hline \multicolumn{4}{|c|}{ Age distribution in years } \\
\hline Mean & 24.28 & 24.01 & \multirow{3}{*}{0.710} \\
\hline Standard deviation & 3.96 & 4.80 & \\
\hline Range & $17-30$ & $16-30$ & \\
\hline \multicolumn{4}{|c|}{ Body Mass Index (BMI kg/m²) } \\
\hline Mean & 27.82 & 23.45 & \multirow{3}{*}{$\mathrm{p}<0.001$} \\
\hline Standard deviation & 3.54 & 2.92 & \\
\hline Range & $21-32$ & $18-29$ & \\
\hline \multicolumn{4}{|c|}{ Menstrual cycle duration (days) } \\
\hline Mean & 40.15 & 31.95 & \multirow{3}{*}{$\mathrm{p}<0.001$} \\
\hline Standard deviation & 10.32 & 4.22 & \\
\hline Range & $27-65$ & $26-48$ & \\
\hline
\end{tabular}

As can be seen from the Table 1 the mean age for the participants in the PCOS group was 24.28 and in the control group it was 24.01 (with a $\mathrm{p}$ value of $\mathrm{p}=0.710$ ) and the difference was statistically insignificant. Average BMI in the PCOS group was 27.82 and in the control group it was 23.45 . The difference was statistically significant (with a p value of $\mathrm{p}<0.001$ ) and shows that PCOS is more frequently associated with increased BMI as compared to normal women. There was also statistically significant difference between the duration of menstrual cycle between the PCOS (40.15 days) and control group (31.95 days) with a $\mathrm{p}$ Value of less than 0.001 Table 1 .

Table 2: Various obstetrical and other physical parameters between the two study groups.

\begin{tabular}{|c|c|c|c|c|c|}
\hline \multirow{2}{*}{ Parameter } & PCOS & Control & Total & \multirow{2}{*}{ Chi-square } & \multirow{2}{*}{ p value } \\
\hline & n $(\%)$ & n $(\%)$ & $\mathbf{N}(\%)$ & & \\
\hline \multicolumn{6}{|l|}{ Infertility } \\
\hline No & $69(87.3 \%)$ & $74(98.7 \%)$ & $143(92.9 \%)$ & \multirow{2}{*}{7.44} & \multirow{2}{*}{$\mathrm{p}<0.05$} \\
\hline Yes & $10(12.7 \%)$ & $1(1.3 \%)$ & $11(7.1 \%)$ & & \\
\hline \multicolumn{6}{|l|}{ Menstrual flow } \\
\hline Oligomenorrhoea & $47(59.5 \%)$ & $14(18.7 \%)$ & $61(39.6 \%)$ & \multirow{2}{*}{26.81} & \multirow{2}{*}{$\mathrm{p}<0.01$} \\
\hline Regular & $32(40.5 \%)$ & $61(81.3 \%)$ & $93(60.4 \%)$ & & \\
\hline \multicolumn{6}{|l|}{ Marital status } \\
\hline Unmarried & $48(60.8 \%)$ & $40(53.3 \%)$ & $88(57.1 \%)$ & \multirow{2}{*}{0.87} & \multirow{2}{*}{0.352} \\
\hline Married & $31(39.2 \%)$ & $35(46.7 \%)$ & $66(42.9 \%)$ & & \\
\hline \multicolumn{6}{|l|}{ Hirsutism } \\
\hline No & $30(38.0 \%)$ & $73(97.3 \%)$ & $103(66.9 \%)$ & \multirow{2}{*}{61.20} & \multirow{2}{*}{$\mathrm{p}<0.001$} \\
\hline Yes & $49(62.0 \%)$ & $2(2.7 \%)$ & $51(33.1 \%)$ & & \\
\hline \multicolumn{6}{|l|}{ Acne } \\
\hline No & $25(32.0 \%)$ & $70(93.0 \%)$ & $95(62.0 \%)$ & \multirow{2}{*}{61.95} & \multirow{2}{*}{$\mathrm{p}<0.001$} \\
\hline Yes & $54(68.0 \%)$ & $5(7.0 \%)$ & $59(38.0 \%)$ & & \\
\hline \multicolumn{6}{|l|}{ Lifestyle pattern } \\
\hline Active & $28(35.4 \%)$ & $61(81.3 \%)$ & $89(57.8 \%)$ & \multirow{2}{*}{33.22} & \multirow{2}{*}{$\mathrm{p}<0.001$} \\
\hline Sedentary & $51(64.6 \%)$ & $14(18.7 \%)$ & $65(42.2 \%)$ & & \\
\hline \multicolumn{6}{|l|}{ Dietary pattern } \\
\hline High carbohydrate & $58(73.4 \%)$ & $27(36.0 \%)$ & $85(55.2 \%)$ & \multirow{2}{*}{21.78} & \multirow{2}{*}{$\mathrm{p}<0.001$} \\
\hline Normal & $21(26.6 \%)$ & $48(64.0 \%)$ & $69(44.8 \%)$ & & \\
\hline
\end{tabular}


Based on the menstrual flow, $59.5 \%$ and $18.7 \%$ of the women with PCOS and the control group respectively had oligomenorrhoea ( $\mathrm{p}$ value <0.001). Among the women with PCOS $60.8 \%$ were married as compared to $53.3 \%$ in control group ( $\mathrm{p}$ value $<0.352$ ). In the PCOS group $12.7 \%$ suffered from fertility deprivation as compared to $1.3 \%$ in the control group and the difference was statistically significant ( $p$ value $<0.05$ ). In the PCOS group $62 \%$ of the patients had features of hirsutism and $68 \%$ had acne compared to $2.7 \%$ and $7 \%$ in control group respectively and the difference reaching statistically significant levels with a $\mathrm{P}$ value of less than 0.001 . A significant portion of patients in PCOS group had sedentary life style $(64.6 \%)$ and a diet rich in carbohydrates $(73.4 \%)$ as compared to control group with $18.7 \%$ patients having sedentary lifestyle and $36 \%$ having high carbohydrate diet $(\mathrm{p}<0.001)$ Table 2.

Table 3: OGTT results between the two study groups.

\begin{tabular}{|c|c|c|c|c|c|c|c|c|}
\hline \multirow{2}{*}{$\begin{array}{l}\text { OGTT (with } 75 \mathrm{gm} \text { of glucose } \\
\text { after } 2 \text { hour) }\end{array}$} & \multicolumn{2}{|c|}{ PCOS } & \multicolumn{2}{|c|}{ Control } & \multicolumn{2}{|c|}{ Total } & \multirow[b]{2}{*}{ Chi-square } & \multirow[b]{2}{*}{ p value } \\
\hline & $\mathbf{n}$ & $\%$ & $\mathbf{n}$ & $\%$ & $\mathbf{N}$ & $\%$ & & \\
\hline Deranged & 32 & 40.5 & 2 & 2.7 & 34 & 22.1 & \multirow{2}{*}{32.02} & \multirow{2}{*}{$\mathrm{P}<0.001$} \\
\hline Normal & 47 & 59.5 & 73 & 97.3 & 120 & 77.9 & & \\
\hline Total & 79 & 100 & 75 & 100 & 154 & 100 & & \\
\hline
\end{tabular}

OGTT was deranged in $40.5 \%$ of patients in PCOS group as compared to $2.7 \%$ in the control group and the difference was statistically significant $(\mathrm{p}<0.001)$, Table 3 .
Overall deranged OGTT and prevalence of PCOS was seen more in patients with higher BMI as compared to patients with normal BMI of less than 25 and the difference was statistically significant $(\mathrm{p}<0.001)$, Table 4 .

Table 4: Relationship between OGTT and prevalence of PCOS with Body Mass Index.

\begin{tabular}{|c|c|c|c|c|c|c|c|c|c|c|}
\hline \multirow{3}{*}{ OGTT } & \multicolumn{8}{|l|}{ BMI $\left(\mathrm{kg} / \mathrm{m}^{2}\right)$} & \multirow{3}{*}{$\begin{array}{l}\text { Fisher's } \\
\text { exact test }\end{array}$} & \multirow{3}{*}{ p value } \\
\hline & \multicolumn{2}{|l|}{$18-25$} & \multicolumn{2}{|c|}{$26-30$} & \multicolumn{2}{|l|}{$>\mathbf{3 0}$} & \multicolumn{2}{|c|}{ Combined } & & \\
\hline & n & $\%$ & n & $\%$ & n & $\%$ & $\mathbf{N}$ & $\%$ & & \\
\hline Deranged & 0 & 0 & 14 & 25.9 & 20 & 90.9 & 34 & 22.1 & \multirow{3}{*}{82.4} & \multirow{3}{*}{$\mathrm{p}<0.001$} \\
\hline Normal & 78 & 100 & 40 & 74.1 & 2 & 9.1 & 120 & 77.9 & & \\
\hline Total & 78 & 100 & 54 & 100 & 22 & 100 & 154 & 100 & & \\
\hline \multirow{3}{*}{ Variables } & BMI $\left(\mathrm{kg} / \mathrm{m}^{2}\right)$ & & & & & & & & \multirow{2}{*}{$\begin{array}{l}\text { Fisher's } \\
\text { exact test }\end{array}$} & \multirow{2}{*}{$P$ value } \\
\hline & \multicolumn{2}{|l|}{$18-25$} & \multicolumn{2}{|c|}{$26-30$} & \multicolumn{2}{|l|}{$>\mathbf{3 0}$} & \multicolumn{2}{|c|}{ Combined } & & \\
\hline & $\mathrm{n}$ & $\%$ & $\mathbf{n}$ & $\%$ & $\mathbf{n}$ & $\%$ & $\mathbf{N}$ & $\%$ & \multirow{4}{*}{41.2} & \multirow{4}{*}{$\mathrm{p}<0.001$} \\
\hline PCOS & 24 & 30.8 & 33 & 61.1 & 22 & 100 & 79 & 51.3 & & \\
\hline Control & 54 & 69.2 & 21 & 38.9 & 0 & 0 & 75 & 48.7 & & \\
\hline Total & 78 & 100 & 54 & 100 & 22 & 100 & 154 & 100 & & \\
\hline
\end{tabular}

Table 5: Relationship between prevalence of hirsutism, acne and infertility with Body Mass Index.

\begin{tabular}{|c|c|c|c|c|c|c|c|c|c|c|}
\hline \multirow{3}{*}{ Variables } & \multicolumn{8}{|c|}{ BMI $\left(\mathrm{kg} / \mathrm{m}^{2}\right)$} & \multirow{3}{*}{$\begin{array}{l}\text { Chi- } \\
\text { square }\end{array}$} & \multirow{3}{*}{ P value } \\
\hline & \multicolumn{2}{|c|}{$18-25$} & \multicolumn{2}{|c|}{$26-30$} & \multicolumn{2}{|c|}{$>\mathbf{3 0}$} & \multicolumn{2}{|c|}{ Combined } & & \\
\hline & $\mathbf{n}$ & $\%$ & $\mathbf{n}$ & $\%$ & $\mathbf{n}$ & $\%$ & $\mathbf{N}$ & $\%$ & & \\
\hline \multicolumn{11}{|l|}{ Hirsutism } \\
\hline No & 76 & 97.4 & 27 & 50 & 0 & 0 & 103 & 66.9 & \multirow{2}{*}{84.25} & \multirow{2}{*}{$\mathrm{p}<0.001$} \\
\hline Yes & 2 & 2.6 & 27 & 50 & 22 & 100 & 51 & 33.1 & & \\
\hline \multicolumn{11}{|l|}{ Acne } \\
\hline No & 62 & 79.5 & 28 & 51.9 & 5 & 22.7 & 95 & 61.7 & \multirow{2}{*}{26.79} & \multirow{2}{*}{$\mathrm{p}<0.001$} \\
\hline Yes & 16 & 20.5 & 26 & 48.1 & 17 & 77.3 & 59 & 38.3 & & \\
\hline \multicolumn{11}{|l|}{ Infertility } \\
\hline No & 78 & 100 & 49 & 90.7 & 16 & 72.7 & 143 & 92.9 & \multirow{3}{*}{19.81} & \multirow{3}{*}{$\mathrm{p}<0.001$} \\
\hline Yes & 0 & 0 & 5 & 9.3 & 6 & 27.3 & 11 & 7.1 & & \\
\hline Total & & 100.0 & & 100.0 & 154 & 100.0 & 154 & 100 & & \\
\hline
\end{tabular}


Table 6: Deranged Serum triglycerides and LDL cholesterol between the two study groups.

\begin{tabular}{|c|c|c|c|c|c|c|c|c|}
\hline \multirow{2}{*}{ Variable } & \multicolumn{2}{|c|}{ PCOS } & \multicolumn{2}{|c|}{ Control } & \multicolumn{2}{|c|}{ Total } & \multirow{2}{*}{ Chi-square } & \multirow{2}{*}{ p Value } \\
\hline & $\mathbf{n}$ & $\%$ & $\mathbf{n}$ & $\%$ & $\mathbf{N}$ & $\%$ & & \\
\hline \multicolumn{9}{|c|}{ Serum triglyceride } \\
\hline Deranged & 18 & 22.78 & 3 & 4 & 21 & 13.64 & \multirow{3}{*}{8.221} & \multirow{3}{*}{$\mathrm{p}<0.05$} \\
\hline Normal & 61 & 77.22 & 72 & 96 & 133 & 86.36 & & \\
\hline Total & 79 & 100 & 75 & 100 & 154 & 100 & & \\
\hline \multicolumn{9}{|c|}{ LDL cholesterol } \\
\hline Deranged & 38 & 48.1 & 26 & 34.67 & 64 & 41.56 & \multirow{3}{*}{2.85} & \multirow{3}{*}{0.0909} \\
\hline Normal & 41 & 58.9 & 49 & 65.33 & 90 & 58.44 & & \\
\hline Total & 79 & 100 & 75 & 100 & 154 & 100 & & \\
\hline
\end{tabular}

Furthermore, a trend was seen where signs and symptoms like infertility, hirsutism and acne were more frequently associated with increased BMI and the difference was statistically significant with a $\mathrm{p}$ value less than 0.001 Table 5. Significantly deranged serum triglyceride levels were seen in $22.78 \%$ of PCOS patients as compared to $4 \%$ in the control group $(\mathrm{p}<0.05)$. Similarly, the LDL cholesterol was deranged in $48.1 \%$ in PCOS group as compared to $34.67 \%$, however the difference was statistically in significant (p value of 0.0909) Table 6. Significant derangements were seen in serum triglycerides and LDL cholesterol when their levels were studied as regards to increase in body mass index and the difference was statistically significant $(\mathrm{p}<0.001)$ Table7.

Table 7: Relationship between prevalence of serum triglycerides and LDL cholesterol with Body Mass Index

\begin{tabular}{|c|c|c|c|c|c|c|c|c|c|c|}
\hline \multirow{3}{*}{ Variable } & \multicolumn{8}{|c|}{ BMI $\left(\mathrm{kg} / \mathrm{m}^{2}\right)$} & \multirow{3}{*}{$\begin{array}{l}\text { Fisher's } \\
\text { exact test }\end{array}$} & \multirow{3}{*}{ P value } \\
\hline & \multicolumn{2}{|c|}{ 18-25 } & \multicolumn{2}{|c|}{ 26-30 } & \multicolumn{2}{|c|}{$>\mathbf{3 0}$} & \multicolumn{2}{|c|}{ Combined } & & \\
\hline & $\mathbf{n}$ & $\%$ & $\mathbf{n}$ & $\%$ & $\mathbf{n}$ & $\%$ & $\mathbf{N}$ & $\%$ & & \\
\hline \multicolumn{11}{|c|}{ LDL cholesterol } \\
\hline Deranged & 8 & 10.26 & 36 & 66.67 & 20 & 90.91 & 64 & 41.56 & \multirow{2}{*}{69.92} & \multirow{2}{*}{$\mathrm{p}<0.001$} \\
\hline Normal & 73 & 89.74 & 18 & 33.33 & 2 & 9.09 & 90 & 58.44 & & \\
\hline Total & 78 & 100 & 54 & 100 & 22 & 100 & 154 & 100 & & \\
\hline \multicolumn{11}{|c|}{ Serum triglyceride } \\
\hline Deranged & 1 & 1.2 & 7 & 12.96 & 13 & 59.09 & 21 & 13.64 & \multirow{2}{*}{42.73} & \multirow{2}{*}{$\mathrm{p}<0.001$} \\
\hline Normal & 77 & 98.72 & 47 & 87.04 & 9 & 40.91 & 133 & 86.36 & & \\
\hline Total & 78 & 100 & 54 & 100 & 22 & 100 & 154 & 100 & & \\
\hline
\end{tabular}

\section{DISCUSSION}

PCOS is one of the most common hormonal conditions presenting with multiple problems such as obesity, menstrual irregularity, hirsutism, infertility or acne. It may also be associated with diabetes, endocrine problems, deranged lipid profile, and cardiovascular disorders. The presentation of the symptoms varies from mild to moderate and the effects of the condition range from adolescence to old age. ${ }^{14}$

Each age presents with different signs of the condition such as in early childhood there may be premature puberty, teenage and early adulthood may be presented with hirsutism, menstrual abnormalities, infertility, obesity, abnormal glucose tolerance and in later life it manifests with the presence of diabetes mellitus, cardiovascular problems, hypertension, and anxiety and depression. ${ }^{15}$ This study aimed to explore the degree of deranged lipid profile and OGTT pattern among PCOS patients and compare the lipid profile and OGTT with normal females. The present study consisted of 79 women with PCOS and 74 women in the control group. The results show that the mean age of both the groups of women with PCOS and the control group was about 24 . Similar results were found in a study conducted by Lekshmiammal et al which showed that the mean age group of women with PCOS was 20.25 years and in the study conducted by Akshaya $\mathrm{S}$ et al, it was 24.98 years. ${ }^{14,16}$

Further, about $91 \%$ of the women with PCOS had irregular menstrual bleeding and about $80 \%$ had oligomenorrhoea and the findings are different from the present study, which depicts that about $60 \%$ of the women with PCOS were oligomenorrheic. The mean BMI among the women with PCOS was $27.82 \mathrm{~kg} / \mathrm{m}^{2}$ while the control group had $23.45 \mathrm{~kg} / \mathrm{m}^{2}$ similar findings 
were found by Akshaya $\mathrm{S}$ et al, which shows that the mean BMI of women with PCOS was $25.9 \mathrm{~kg} / \mathrm{m}^{2}{ }^{14}$ About $61 \%$ of the unmarried women and $39 \%$ of the married women had PCOS in the present study. According to Yousuf $\mathrm{R}$ et al, the study samples consisted of both married and unmarried groups, who were within the age group of 19 to 30 years. ${ }^{17}$

In the present study $13 \%$ suffered from fertility deprivation, however in the study conducted by Yousuf $\mathrm{R}$ et al, about $74 \%$ of the women with PCOS suffered from while the study conducted by Lekshmiammal et al reveals the prevalence of about $57 \%$ infertility among the women with PCOS. ${ }^{16,17}$

The high incidence if infertility among women with PCOS is probably due to the inadequate development of the ovum of the failure to release the ovum during the ovulation period. It also leads to irregular menstrual periods and oligomenorrhoea. ${ }^{12}$

About $62 \%$ of the women with PCOS in the present study had hirsutism and $68 \%$ of the women with PCOS had acne. In the study conducted by Yousuf $\mathrm{R}$ et al, about $31 \%$ of the women were hirsute. ${ }^{17}$ Yuan C et al, state that hyperandrogenism is commonly present in women with PCOS and acne and hirsutism are the clinical signs of androgen excess. ${ }^{13}$ The prevalence of acne in PCOS women ranges from $10 \%$ to $34 \%$, which is higher than normal women. Hirsutism and acne are the common clinical features of androgen excess. ${ }^{7}$

In the present study about $64 \%$ of the patients with PCOS were sedentary workers while from the control group only $19 \%$ followed a sedentary lifestyle. In the study conducted by Sedighi $\mathrm{S}$ et al it was observed that there was a significant association between PCOS and low physical activity. ${ }^{18}$

The OGTT test of the present study revealed that about $41 \%$ of the study patients with PCOS had deranged oral glucose tolerance. Similar results were found in a study conducted by Coles $\mathrm{N}$ et al which showed that $16 \%$ of the patients had impaired glucose tolerance. ${ }^{15}$ Traub also states that women with PCOS show a higher degree of insulin resistance. ${ }^{19}$ High degree of correlation has also been observed between hyperandrogenism (causes hirsutism) and insulin resistance in PCOS women. ${ }^{20}$ Similarly, Saxena $\mathrm{P}$ et al observed that about $83 \%$ of the non-obese and $93 \%$ of the obese women with PCOS showed insulin resistance. ${ }^{21}$

The present study results show that about $91 \%$ of the women with PCOS with deranged OGTT had BMI above $30 \mathrm{~kg} / \mathrm{m}^{2}$ and about $26 \%$ had a BMI in between 26 to 30 $\mathrm{kg} / \mathrm{m}^{2}$ and all the women with normal BMI had normal OGTT. The findings of the present study are supported by Saxena P, et al. which reveals that $10.3 \%$ of women with abnormal GTT, $31 \%$ with deranged lipid profile, and $93 \%$ with insulin resistance were overweight. ${ }^{21}$ The study conducted by Akshaya $\mathrm{S}$ et al also shows that deranged was not significant to obesity. ${ }^{14}$

The study results show that among the women with PCOS and BMI above 30, about $91 \%$ had deranged LDL cholesterol values and about 59\% had deranged serum triglyceride levels. About $67 \%$ and $12.9 \%$ of the women with BMI between 26 to $30 \mathrm{~kg} / \mathrm{m}^{2}$ had deranged LDL cholesterol and serum triglyceride respectively. About $10.6 \%$ of the women with normal BMI had deranged LDL cholesterol.

In the study conducted by Akshaya S et al about $39 \%$ of the women with PCOS were obese and about $14 \%$ were lean who had deranged lipid profile. The difference of deranged lipid profile was statistically significant with both obese and non-obese women. ${ }^{14}$ In a study conducted by Shoaib et al, the results reveal no correlation between $\mathrm{BMI}$ and serum triglyceride $(\mathrm{r}=0.00, \mathrm{P}=0.001)$ and insignificant and weak correlation between BMI and serum cholesterol. An insignificant, very weak positive correlation is observed between BMI and serum LDL levels $(\mathrm{r}=0.04, \mathrm{P}=0.56) .{ }^{22}$ Lath $\mathrm{R}$ et al reveal significant $(p<0.05)$ high levels of serum LDL among PCOS women in their study. ${ }^{23}$

A significant association $(\mathrm{p}<0.001)$ between PCOS and obesity is observed in the present study. All the women with BMI above $30 \mathrm{~kg} / \mathrm{m}^{2}$ were diagnosed with PCOS. About $61 \%$ and $31 \%$ of the women with PCOS had BMI between 26 to $30 \mathrm{~kg} / \mathrm{m}^{2}$ and below $25 \mathrm{~kg} / \mathrm{m}^{2}$ respectively. In the study conducted by Akshaya $\mathrm{S}$ et al, about $56 \%$ of the women with PCOS had BMI above 23 and were at high risk for development of comorbidities such as hypertension, deranged lipid profile and impaired insulin resistance. ${ }^{14}$

The dietary pattern of the patients with PCOS showed that about $73 \%$ of the women had a high intake of carbohydrate while only $27 \%$ of the control group consumed a diet rich in carbohydrate. The study conducted by Ahmadi A et al also reveals that the women with PCOS consumed more calories and fats than healthy women which were highly significant. ${ }^{24}$

The comparison of the different symptoms of PCOS in relation to BMI of the individuals showed that all the women with BMI of more than $30 \%$ had hirsutism and $77 \%$ and $27 \%$ had acne and infertility respectively.

About $50 \%, 48 \%$ and $9 \%$ of the women presented with hirsutism, acne and infertility respectively in women with BMI between 26 and 30. These figures were much higher than the women who had normal BMI as only about $3 \%$, $20 \%$ and $13 \%$ of the women presented with hirsutism, acne and obesity while no woman had infertility. These findings are supported by the study conducted by Lekshmiammal et al which revealed that PCOS and hyperandrogenism was significantly more common in obese patients than the non-obese with $(\mathrm{p}<0.05)$, it also 
revealed that obesity was also strongly associated with irregular menstrual cycle and infertility and about $57 \%$ of the patients had hirsutism and $99 \%$ and $80 \%$ had irregular menstrual bleeding and oligomenorrhoea. ${ }^{16}$

\section{CONCLUSION}

PCOS is a common health problem among adolescents and young adults. Adequate tests must be carried out to explore the underlying conditions and the complications present. The current study concludes that PCOS is a metabolic as well as a reproductive endocrinopathy with menstrual disturbances and infertility, and may include peripheral insulin resistance, dyslipidemia, diabetes mellitus and cardiovascular conditions. Obesity, sedentary lifestyle, and dietary factors can be modified to improve the health condition of the women with PCOS.

An active lifestyle with regular exercises, balanced diet and maintaining a regular check on weight gain can help reduce the symptoms. Early diagnosis and management of the condition can prevent the onset of certain diseases such as type 2 diabetes mellitus, atherosclerosis and coronary artery disease. Periodic monitoring of insulin resistance and lipid profile, and annual OGTT monitoring, especially for overweight PCOS patients may help in reducing the instances of further complications.

The study has tried to explore the deranged lipid and OGTT pattern among women with PCOS. However, the cause and effect relationship may not be visible accurately in such a small sample. A larger sample size would further help to provide a more validated data.

\section{Funding: No funding sources}

Conflict of interest: None declared

Ethical approval: The study was approved by the Institutional Ethics Committee

\section{REFERENCES}

1. Pasquali R, Stener-Victorin E, Yildiz BO, Duleba AJ, Hoeger K, Mason H, et al. Forum: research in polycystic ovary syndrome today and tomorrow. Clin Endocrinol (Oxf). 2011;74:424-33.

2. Balen A, Conway G, Kaltsas G. Polycystic ovary syndrome: the spectrum of the disorder in 1741 patients. Hum Reprod. 1995;10:2107-11.

3. Sirmans SM, Pate KA. Epidemiology, diagnosis, and management of polycystic ovary syndrome. Clin Epidemiol. 2013;6:1-13.

4. Nidhi C, Venkatram P, Raghuram N, Amritanshu R. Prevalence of polycystic ovarian syndrome in Indian adolescents. J Pediatr Adolescent Gynecol. 2001;24:223-7.

5. Sozen I, Arici A. Hyperinsulinism and its interaction with hyperandrogenism in polycystic ovary syndrome. Obstet Gynecol Surv. 2000;55:321-8.

6. Farquhar CM, Birdsall M, Manning P, Mitchell JM, France JT. The prevalence of polycystic ovaries on ultrasound scanning in a population of randomly selected women. Aust NZ Obstet Gynaecol. 1994;34:67-72.

7. Ramanand SJ, Ghongane BB, Ramanand JB, Patwardhan MH, Ghanghas RR, Jain SS. Clinical characteristics of polycystic ovary syndrome in Indian women. Indian $\mathrm{J}$ Endocrinol Metab. 2013; 17:138-45.

8. Lord J, Thomas R, Fox B, Acharya U, Wilkin T. The central issue? visceral fat is a good marker of insulin resistance and metabolic disturbances in women with polycystic ovary syndrome. BJOG. 2006;113:12039.

9. Ovalle F, Azziz R. Insulin resistance, polycystic ovary syndrome, and type 2 diabetes mellitus. Fertil Steril. 2002;77(6):1095-105.

10. Pelusi B, Gambineri A, Pasquali R. Type 2 diabetes and the polycystic ovary syndrome. Minerva Ginecol. 2004;56(1):41-51.

11. Kalra A, Nair S, Rai L. Association of obesity and insulin resistance with dyslipidemia in Indian women with polycystic ovarian syndrome. Indian J Med Sci. 2006;60:447-53.

12. Hart R. PCOS and infertility. Panminerva Med. 2008;50:305-14.

13. Yuan C, Liu X, Mao Y, Diao F, Cui Y, Liu J. Polycystic ovary syndrome patients with high BMI tend to have functional disorders of androgen excess: a prospective study. J Biomed Res. 2016;30(3):197202.

14. Akshaya S, Bhattacharya R. Comparative study of metabolic profile of women presenting with polycystic ovary syndrome in relation to body mass index. Int J Reprod Contracept Obstet Gynecol 2016;5:2561-5.

15. Coles N, Bremer K, Kives S, Zhao X, Hamilton J. Utility of the oral glucose tolerance test to assess glucose abnormalities in adolescents with polycystic ovary syndrome. J Pediatr Adolesc Gynecol. 2016;29(1):48-52.

16. Lekshmiammal P, Krishnadas S. Hyperinsulinemia in polycystic ovary syndrome. J Med Sci Clin Res. 2017;5(5):21286-92.

17. Yousuf R, Khan M, Kounsar Z, Ahangar S, Lone WA. Polycystic ovarian syndrome: clinical correlation with biochemical status. Surg Sci. 2012;3:245-8.

18. Sedighi S, Akbari AAS, Afrakhteh M, Esteki T, Majd AH, Mahmoodi Z. Comparison of lifestyle in women with polycystic ovary syndrome and healthy women. Glob J Health Sci. 2015;7:228-34.

19. Traub ML. Assessing and treating insulin resistance in women with polycystic ovarian syndrome. World J Diabetes. 2011;2:33-40.

20. Çelik E, Türkçüoğlu I, Ata B, Karaer A, Kırıcı P, Eraslan S, et al. Metabolic and carbohydrate characteristics of different phenotypes of polycystic ovary syndrome. J Turkish German Gynecol Assoc. 2016;17(4):201-8. 
21. Saxena P, Prakash A, Nigam A, Mishra A. PCOS: is obesity a sine qua non? a clinical, hormonal and metabolic assessment in relation to BMI. Indian $\mathrm{J}$ Endocrinol Metab. 2012;16(6):996-9.

22. Shoaib OM, Mustafa SM, Nourein IH. Serum lipid profile of polycystic ovary syndrome in Sudanese women. Int J Med Sci Pub Health. 2015;4(11):160510.

23. Lath R, Shendye R, Jibhkate A. Insulin resistance and lipid profle in polycystic ovary syndrome. Asian J Biomed Pharm Sci. 2015;5(48):30-5.

24. Ahmadi A, Akbarzadeh M, Mohammadi F, Akbari M, Jafari B, Tolide-Ie HR. Anthropometric characteristics and dietary pattern of women with polycystic ovary syndrome. Indian $\mathrm{J}$ Endocrinol Metab. 2013;17(4):672-6.

Cite this article as: Phutela IR, Pandit $\mathrm{BH}$, Ashraf A, Wani SA, Mehraj Ud Din. Comparative study to evaluate the prevalence of deranged lipid profile and oral glucose tolerance test in polycystic ovarian syndrome patients with normal females: a prospective observational study. Int J Reprod Contracept Obstet Gynecol 2017;6:5407-14. 